\title{
SOSIALISASI APLIKASI HEC (HYBRID EVAPORATIVE COOLER) DI SMK PGRI CIKAMPEK
}

\author{
Reni Rahmadewi ${ }^{1)}$, Rizal Hanifi'2), Tesa Nur Padilah3), Vita Efelina ${ }^{4}$, Endah Purwanti ${ }^{4}$, \\ Sarah Dampang ${ }^{5}$
}

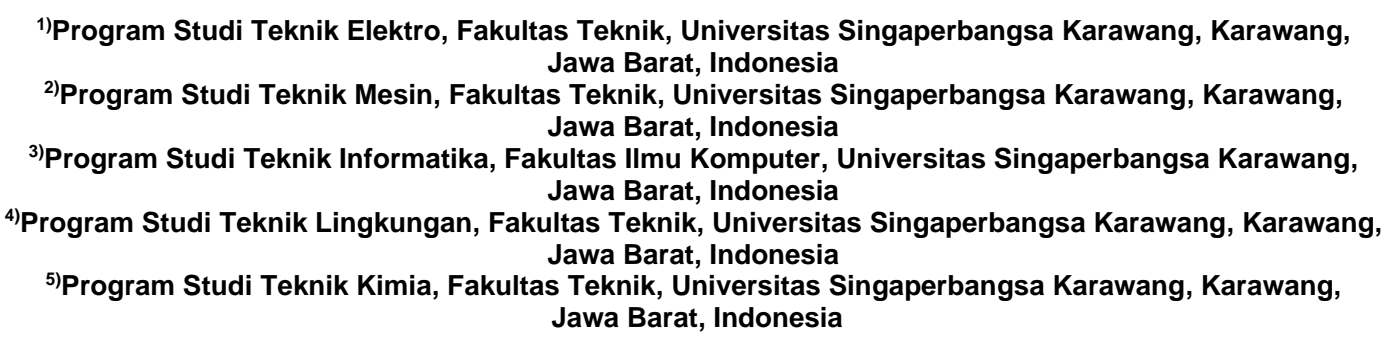

Corresponding author: Reni Rahmadewi

reni.rahmadewi@staff.unsika.ac.id

\section{Diterima 29 November 2021, Disetujui 01 Desember 2021}

\begin{abstract}
ABSTRAK
Aplikasi HEC atau yang disebut dengan Hybrid Evaporate Cooler, aplikasi ini dibuat menggunakan pengembangan operasi pada aplikasi android berbasis web yaitu MIT APP INVENTOR. Aplikasi yang diinstal pada smartphone/android untuk mengontrol alat HEC. Sosialisasi ini dilaksanakan di SMK PGRI Cikampek khususnya siswa jurusan RPL (Rekayasa Perangkat Lunak) sehingga siswa bisa mengetahui software MIT APP INVERTOR dan siswa diharapkan bisa membuat aplikasi secara mandiri. Setelah Aplikasi diinstal di android, siswa bisa menggunakan menu yang ada pada aplikasi HEC diantaranya adalah tombol go to screen 3 , tombol back to screen 1 , memilih perangkat bluetooth, menampilkan data kelembapan, pengiriman data ke database dengan media firebase web, input melalui suara, pemilihan input kecepatan ON/OFF. Siswa bisa memilih tombol menu yang diinginkan sesuai dengan menu yang ada pada aplikasi. Software MIT APP INVENTOR bisa terhubung dengan alat HEC dengan menyalakan Bluetooth pada android terlebih dahulu. Selain meng-edukasi secara teknologi, kami juga memberi memberikan pengetahuan bagaimana menginstall dan penggunaan aplikasi HEC pada android yaitu menggunakan software MIT APP Inventor.
\end{abstract}

Kata-kata kunci: HEC (hybrid evaporative cooler); MIT APP inventor; bluetooth.

The HEC application or what is called the Hybrid Evaporate Cooler, this application was created using the development of operations on a web-based android application, namely MIT APP INVENTOR. Application installed on smartphone/android to control HEC tools. This socialization was carried out at SMK PGRI Cikampek, especially students majoring in RPL (Software Engineering) so that students could know the MIT APP INVERTOR software and students were expected to be able to make applications independently. After the application is installed on android, students can use the menus in the HEC application including the go to screen 3 button, the back to screen 1 button, selecting a bluetooth device, displaying humidity data, sending data to the database using firebase web media, input via voice, ON/OFF speed input selection. Students can choose the desired menu button according to the menu in the application. The MIT APP INVENTOR software can connect with HEC devices by turning on Bluetooth on Android first. In addition to educating technology, we also provide knowledge on how to install and use the HEC application on Android, using the MIT APP Inventor software.

Keywords: HEC (hybrid evaporative cooler); MIT APP inventor; bluetooth.

\section{PENDAHULUAN}

Melihat teknologi yang demikian pesat perkembangannya dalam bidang komputer maupun dibidang lainnya, menuntut kita mengharuskan menguasai ataupun mengerti cara penggunaannya dan cara kerja teknologi tersebut (F.Sitanggang \& Martha, 2020). Perkembangan teknologi saat ini tidak hanya terjadi pada perangkat keras (hardware) tetapi juga dalam bidang perangkat lunak (software) (M. S. Afdilah, 2019).

Perkembangan teknologi yang begitu 
pesat memiliki peran penting yaitu agar dapat meyediakan berbagai kemudahan bagi masyarakat saat ini, misalnya untuk mempermudah pekerjaan, melihat informasi terbaru tentang kehidupan sekitar yang sedang terjadi (Farid, 2020). Oleh karena itu dilakukan pengembangan teknologi khusus nya dalam bidang aplikasi untuk memudahkan pengoperasian sistem (I. Muliyawati \& A. Wibisono, 2021).

Aplikasi merupakan suatu perangkat yang dibuat khusus untuk memenuhi kebutuhan berbagai aktivitas dan pekerjaan (A. Susanto, 2018). MIT APP INVERTOR adalah sebuah software dengan sumber yang terbuka untuk semua orang yang ingin menggunakannya, berfungsi untuk membuat aplikasi perangkat lunak untuk sistem operasi android (H. R. P. Negara, et al., 2019). Menggunakan bahasa pemograman java, kawa scheme. Hanya dengan mendrag dan drop objek visual untuk software aplikasi yang ingin dibuat (N. Sudin \& M. K. G. Umar, 2020).

Tujuan operasi awal adalah untuk sebuah smartphone android dalam menggunakan Produk Hybrid Evaporative Cooler (HY EVAPCO) Berfungsi untuk menyalakan dan mematikan (ON/OFF) berbasis push button/voice control selain itu bisa memonitoring kelembapan dalam monitor aplikasi (M. A. Nur, et al., 2021). Maka dibuat aplikasi yang bernama HEC APP dibuat menggunakan aplikasi MIT APP INVENTOR yang diharapkan bisa membuat penggunaan alat HY EVAPCO menjadi lebih praktis dan mudah dalam pengoprasiannya,

\section{METODE}

Sebelum melakukan sosialisasi, tim melakukan survei terlebih dahulu ke SMK PGRI Cikampek. Tim melakukan pertemuan dengan Guru yang ada di SMK dan ada beberapa jurusan yang ada di sekolah salah satunya jurusan RPL (Rekayasa Perangkat Lunak) atau jurusan komputer. Tim menyiapkan materi mengenai software MIT APP INVENTOR. Hal ini bertujuan untuk dilakukan sosialisasi dan pelatihan, karena hasil wawancara dengan Guru yang ada di SMK PGRI Cikampek ini, siswa masih kurang pengetahuannya mengenai proses pembuatan aplikasi terutama menggunakan software MIT APP INVENTOR. Maka tim mengadakan forum diskusi/sosialisasi dengan jumlah peserta siswa terbatas dan menerapkan protokol Kesehatan.

Metode yang digunakan adalah metode kualitatif. Metode kualitatif sebagai prosedur pengabdian yang menghasilkan data deskriptif berupa kata-kata tertulis atau lisan dari orang-orang atau perilaku yang dapat diamati. Bentuk kualitatif yang dipilih adalah pengabdian deskriptif yang merupakan suatu metode pengabdian yang menggambarkan semua data atau keadaan subjek atau objek pengabdian yang dianalisis dan dibandingkan berdasarkan kenyataan yang sedang berlangsung. pengabdian ini berupa penyuluhan meliputi sosialisasi dan pelatihan. Sosialisasi yang kami lakukan yaitu dengan mengumpulkan siswa dalam satu kelas SMK PGRI Cikampek kami melakukan sosialisai dengan cara mempersentasikan pengenalan alat HY EVAPCO dan aplikasi HEC APP serta menjelaskan komponen apa saja yang dipakai yang diharapkan menjadi sebuah acuan untuk siswa berkarya, serta melakukan pelatihan untuk membuat aplikasi menggunakan MIT APP INVENTOR kepada siswa dan guru.

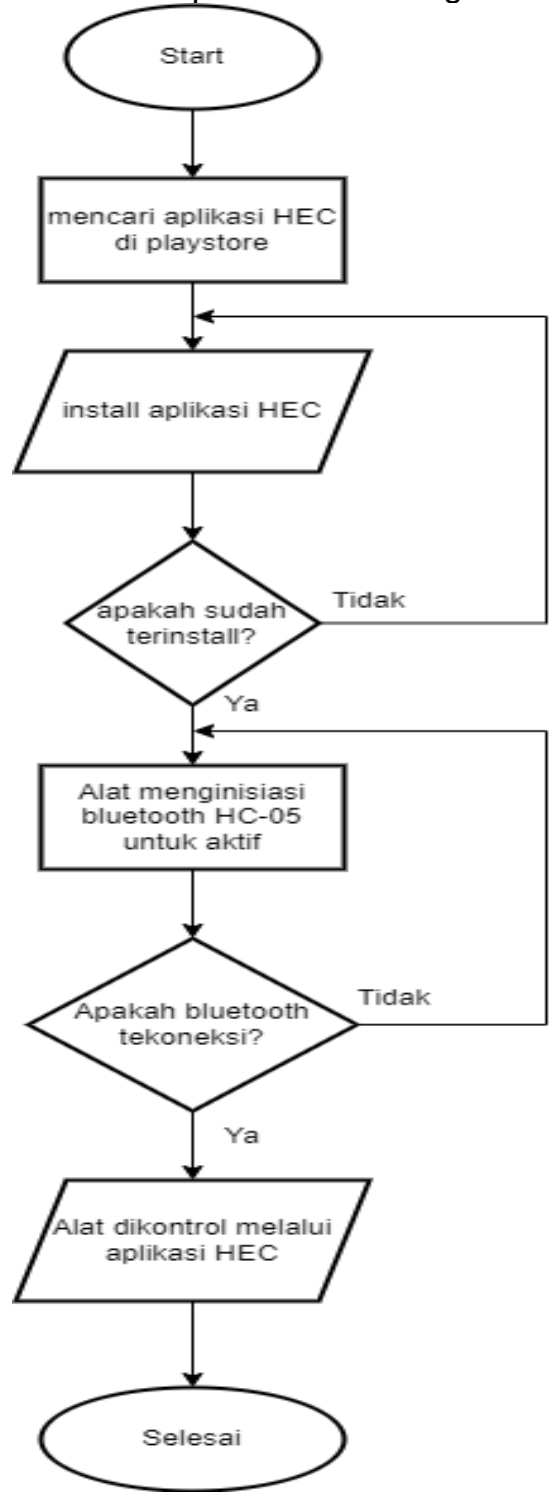

Gambar 1. Flowchart sistem

Adapun alat dan bahan yang digunakan didalam membuat Aplikasi HEC 
APP ini adalah menyediakan laptop dan smartphone kemudian instal aplikasi MIT APP INVERTOR. Setelah aplikasi diinstal, siswa bisa menguji aplikasi dengan menyalakan bluetooth terlebih dahulu agar bisa terhubung dengan alat HY EVAPCO, dan menggunakan aplikasi HEC yang sudah diinstal siswa dan guru secara bergantian. Berikut ini adalah flowchart sistem yang dapat dilihat pada Gambar 1. Gambar 1 flowchart system menjelaskan tata cara mendownload aplikasi dan tata cara penggunaan yang sesuai dengan perintah diinginkan.

\section{HASIL DAN DISKUSI}

Sosialisasi ini bertujuan untuk mengenalkan alat HY EVAPCO yang kami buat sekaligus memberi pelatihan cara pembuatan aplikasi kepada siswa PRL SMK PGRI Cikampek. Di bawah ini merupakan gambar proses sosialisasi alat HY EVAPCO :

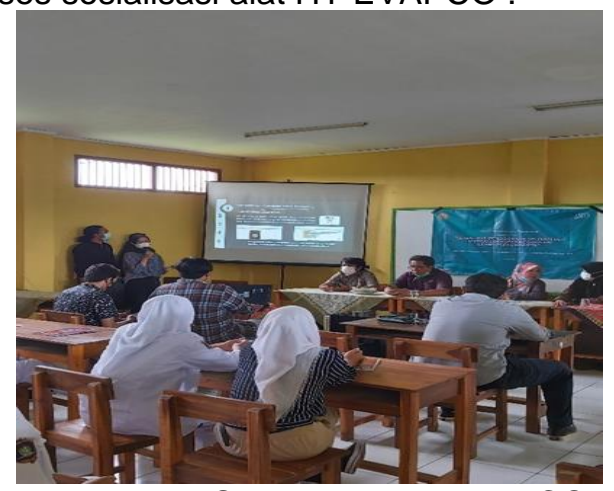

Gambar 2. Sosialisasi HY EVAPCO

Setelah melakukan sosialisasi setelah itu dilakukan pelatihan pembuatan aplikasi menggunakan MIT APP INVENTOR dari mulai cara penginstalan aplikasi sampai proses pembuatan aplikasi semua dijelaskan secara rinci. Dibawah ini merupakan gambar proses pelatihan pembuatan aplikasi menggunakan MIT APP INVENTOR :

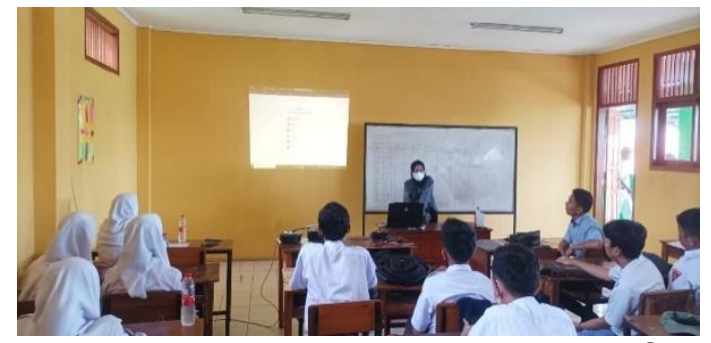

Gambar 3. Pelatihan MIT APP INVENTOR

Software MIT APP INVENTOR dapat digunakan oleh siswa dan guru untuk mengoperasikan HY EVAPCO ataupun dijadikan media untuk belajar dan diharapkan dapat mengembangkan aplikasi.

Cara mengintal aplikasi HEC adalah pilih aplikasi Bernama HEC App dengan nama file dokumen HYBRID Cooler App, klik dan install aplikasi pada android, aplikasi sudah bisa digunakan dan siap dihubungkan pada alat dengan menyalakan Bluetooth. Menu aplikasi HEC dapat dilihat pada gambar 4 berikut ini: berikut:

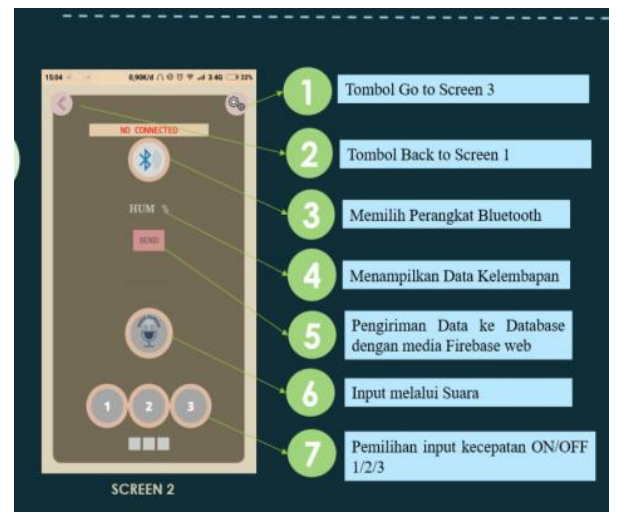

Gambar 4. Menu alikasi HEC

Hasil dari sosialisasi aplikasi HEC ini bisa dimanfaatkan untuk meningkatkan pengetahuan siswa mengenai software MIT APP Inventor. Baik itu cara menginstal dan bagaimana cara menggunakan software tersebut.

\section{SIMPULAN DAN SARAN}

Berdasarkan hasil pengabdian yang telah dilaksanakan, dapat diambil beberapa kesimpulan yakni : 1). Siswa dan Guru jurusan RPL(rekayasa perangkat lunak) SMK PGRI CIKAMPEK memperoleh pengetahuan dan ilmu setelah dilaksanakan sosialisasi dan pelatihan mengenai aplikasi HEC, 2) Siswa sudah bisa mengetahui bagaimana cara menginstal dan menggunakan aplikasi HEC.

\section{UCAPAN TERIMAKASIH}

Ucapan terima kasih disampaikan kepada siswa SMK PGRI Cikampek khususnya siswa jurusan RPL.

\section{DAFTAR RUJUKAN}

F. SITANGGANG, MARTHA OKTAVIANI and Fathoni, "Rancang Bangun Mobile Application Permintaan Barang di PT. Mazosin Perkasa Teknik (MPT) Menggunakan Tools Massachusetts Institute of Technology (MIT) APP Inventor," Sriwijaya University, 2020.

M. S. Afdilah, "Rancang Bangun Alat Monitoring Kelembaban Tanah Berbasis Andoroin Dengan Modul Bluetooth Dan Program MIT App Inventor 2," UNIVERSITAS 17 AGUSTUS 1945 SURABAYA, 2019.

Farid Miftah Fauzi, "Rancang Bangun Inkubator Bayi Dengan Kamera Pengawas Berbasis Aplikasi Android," Universitas 
Pendidikan Indonesia, 2020.

I. Muliyawati, A. Wibisono, P. Studi, P. Teknologi, F. Pendidikan, and M. IImu, "RANCANG BANGUN APLIKASI VIRTUAL TOUR HAJI DAN UMROH" vol. 2, no. 1, pp. 29-38, 2021.

A. Susanto, "Rancang Bangun Aplikasi Android Untuk Kontrol Lampu Gedung Menggunakan Media Bluetooth Berbasis Arduino Uno," J. Tek., vol. 7, no. 1, pp. 51-58, 2018, doi: 10.31000/jt.v7i1.949.

H. R. P. Negara, S. Syaharuddin, K. R. A. Kurniawati, V. Mandailina, and F. H. Santosa, "Meningkatkan Minat Belajar Siswa Melalui Pemanfaatan Media Belajar Berbasis Android Menggunakan Mit App Inventor," SELAPARANG J. Pengabdi. Masy. Berkemajuan, vol. 2, no. 2, p. 42, 2019, doi: 10.31764/jpmb.v2i2.887.

N. Sudin, I. Djufri, and M. K. G. Umar, "Rancang Bangun Sistem Pengontrol Lampu Rumah Berbasis Mikrokontroler Arduino Uno Menggunakan Smartphone," J. IIm. IIk. - IImu Komput. Inform., vol. 3, no. 2, pp. 52-61, 2020, doi: 10.47324/ilkominfo.v3i2.102.

M. A. Nur, N. M. Baussa, H. Nirwana, and F. Ulfiah, "Rancang Bangun Pendeteksi Keberadaan Sepeda Motor Berbasis Bluetooth," no. September, pp. 258261, 2021. 